\title{
Comparison Between NIST and AF Laser Energy Standards Using High Power Lasers
}

\begin{tabular}{|c|c|}
\hline Volume 112 & Number 5 \\
\hline $\begin{array}{l}\text { Xiaoyu Li, Thomas Scott (Retired), } \\
\text { and Chris Cromer }\end{array}$ & $\begin{array}{l}\text { We report the results of a high-energy } \\
\text { laser calorimeter comparison conducted by } \\
\text { the National Institute of Standards and }\end{array}$ \\
\hline $\begin{array}{l}\text { National Institute of Standards } \\
\text { and Technology, } \\
\text { Boulder, CO } 80305\end{array}$ & $\begin{array}{l}\text { Technology (NIST), Boulder, Colorado } \\
\text { and the U.S. Air Force Primary Standards } \\
\text { laboratory (AFPSL), Heath, Ohio. A laser } \\
\text { power meter, used as a transfer standard, } \\
\text { was calibrated at each laboratory, sequen- } \\
\text { tially, and the measurement results were }\end{array}$ \\
\hline David Cooper and & compared. These measurements were \\
\hline Steven Comisford & $\begin{array}{l}\text { performed at a nominal power of } 800 \mathrm{~W} \\
\text { and a wavelength of } 10.6 \mu \mathrm{m} \text { using }\end{array}$ \\
\hline $\begin{array}{l}\text { Air Force Primary Standards } \\
\text { Laboratory, } \\
\text { Heath, OH } 43056\end{array}$ & $\begin{array}{l}\mathrm{CO}_{2} \text { lasers. Excellent measurement } \\
\text { agreement }(1.02 \%) \text { was demonstrated, } \\
\text { which was well within each of the } \\
\text { expanded uncertainties from the two } \\
\text { laboratories involved in this comparison. }\end{array}$ \\
\hline
\end{tabular}

September-October 2007

xiaoyu@boulder.nist.gov

tomrscott@Wyoming.com

cromer@boulder.nist.gov

david.cooper@afmetcal.af.mil

steve.comisford@afmetcal.af.mil

\begin{abstract}
Key words: BB calorimeter; beamsplitter; chopper wheel; comparison; high-energy laser; K-series calorimeter; monitor detector; responsivity; transfer standard.
\end{abstract}

Accepted: October 12, 2007

Available online: http://www.nist.gov/jres

\section{Introduction}

In the 1970s, the U.S. Air Force (AF) funded NIST (formerly NBS) to develop two primary reference standards for the measurement of high-power laser radiation emitted by the extremely large lasers being developed by the Department of Defense as potential weapons systems. These lasers were being designed to produce hundreds of kilowatts or more of CW (continuous wave) power and, at that time, no accurate measurement standards were available for measuring their power output. Consequently, the AF funded NIST to design and construct two large, electrically calibrated calorimeters to be used to measure the output power of the large lasers and to calibrate other detectors being used for this purpose.
In 1973, NIST scientists finished the design and construction of the BB1 [1] calorimeter for measuring the output of lasers having powers up to $100 \mathrm{~kW}$. In 1978 , NIST finished construction and testing of a second calorimeter, BB2 [2], which was similar to BB1 but had some additional improvements. After thorough testing and characterization, both calorimeters were delivered to the AFPSL, where they have been maintained and operated since that time. While both calorimeters are large (approximately $400 \mathrm{~kg}$ each), they are transportable and are carried in a customized, instrumented trailer when used for remote calibrations at high-energy laser sites around the country.

In 1999, the BB1 calorimeter was sent back to NIST for general refurbishment and electronic system upgrade. At the same time, engineers at NIST also 
made two major modifications to the system: (1) an external cooling water loop was added to allow the calorimeter to be cooled more quickly and easily, and (2) sensors from the backscatter and spillover monitors were modified to extend the wavelength capability of the calorimeter. A year later, the BB2 calorimeter was sent back to NIST for the same refurbishment, upgrade and modifications. All work on both calorimeters was completed in 2001. Since the modifications were quite extensive, a comparison between the NIST and the AF standards was deemed advisable to confirm that the AF standards (and the associated measurement system) were still in agreement with those of NIST.

\section{Comparison Procedure}

Due to the physical sizes of the BB1 and BB2 calorimeters compared to the space limitation of the NIST high-power laser laboratory, we could not directly compare them with the NIST high-energy standard calorimeter; consequently, we decided to conduct the comparison using a transfer standard. The transfer standard was a commercially available, water-cooled, absorbing-disc type power meter. The meter had been thoroughly studied at NIST for the past ten years and found to have a good repeatability and spatial uniformity. Additionally, the nonlinearity of the detector is small and has been well characterized. The comparison process consisted of three primary steps. First, the transfer standard responsivity (in units of $\mathrm{mV} / \mathrm{W}$ ) was calibrated at the NIST high-power standard Laboratory. Next, it was sent to AFPSL for calibration. Finally, the transfer standard was returned to NIST where it was then recalibrated and the final NIST calibration result was determined by averaging the two individual NIST calibration results.

\section{NIST Measurement System}

The NIST high-power $\mathrm{CO}_{2}$ laser measurement system (Fig. 1) consists of a high power standard calorimeter (designated as a K-series calorimeter [3]), a beamsplitter, a monitor detector, a $\mathrm{CO}_{2}$ laser, two optical shutters, and a data acquisition system.

The K-series calorimeter is an electrically calibrated calorimeter, which is capable of energy measurements in the range $300 \mathrm{~J}$ to $3000 \mathrm{~J}$. It is typically used to measure $\mathrm{CW}$ lasers radiation at powers of $5 \mathrm{~W}$ to $1000 \mathrm{~W}$ for wavelengths of $1.06 \mu \mathrm{m}$ and $10.6 \mu \mathrm{m}$. This calorimeter has been in constant use as a standard over the past forty years and has shown little or no change in response characteristics during this time period. An optical chopper wheel with reflecting blades was used as a beamsplitter, and a suitable power meter was used as a monitor detector to detect any variation in laser power during the measurements.

The NIST calibration procedure entailed two primary steps. First, with shutter 2 closed, shutter 1 was opened, exposing the monitor detector to the laser beam and allowing it to reach a steady-state condition (i.e., waiting for a period seven times the time constant of the detector). Then, shutter 2 was also opened, exposing the K-series calorimeter to the beam. After the desired time interval (chosen to keep the total absorbed energy within the operational limits of the $\mathrm{K}$ calorimeter), both shutters were closed simultaneously. Thus, for the time period that shutter 2 was open, the $\mathrm{K}$-series calorimeter recorded the total energy in the transmitted laser beam and the monitor detector recorded average power in the reflected laser beam. Since this time interval was accurately measured, the average power in the transmitted beam could be calculated. In the second step, the $\mathrm{K}$-series calorimeter was replaced

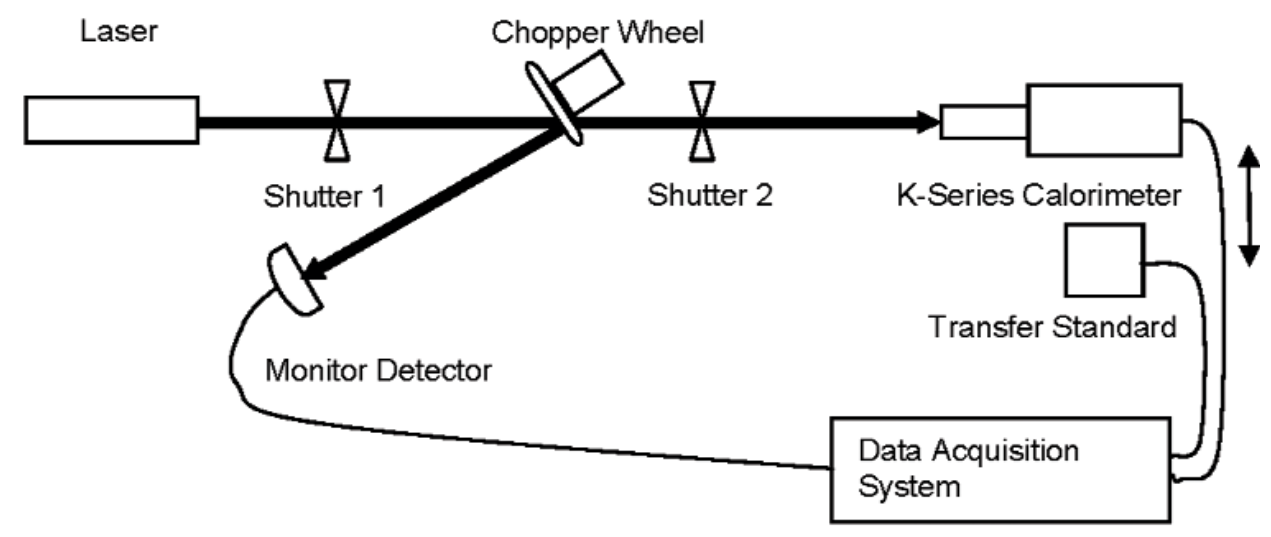

Fig. 1. NIST Measurement System. 
by the transfer standard and the two shutters were opened simultaneously. After waiting for both detectors to reach a steady-state condition (i.e., waiting for a period seven times the time constant of the slowest detector), the average power of each detector output was recorded. By combining the two sets of measurement data (using the monitor detector output to correct for any power variations during the process), the responsivity of the transfer standard was calculated. This pair of steps was performed multiple times and an average responsivity was calculated.

\section{AFPSL Measurement System}

The AFPSL high-energy laser measurement system (Fig. 2) consists of a $\mathrm{BB} 2$ calorimeter, a $\mathrm{CO}_{2}$ laser, a beamsplitter, an optical shutter and a data acquisition system.

The $\mathrm{BB} 1$ and $\mathrm{BB} 2$ calorimeters are the electrically calibrated calorimeters with the enclosed cooling water circulation systems. The BB1 calorimeter measures energy in the range $30 \mathrm{~kJ}$ to $6 \mathrm{MJ}$ using $\mathrm{CW}$ lasers having power outputs in the range $200 \mathrm{~W}$ to $100 \mathrm{~kW}$, and the $\mathrm{BB} 2$ calorimeter measures energy in the range $30 \mathrm{~kJ}$ to $2.5 \mathrm{MJ}$ using $\mathrm{CW}$ lasers having power outputs in the range $200 \mathrm{~W}$ to $100 \mathrm{~kW}$.

A gold-plated chopper wheel with reflective blades is used as the beamsplitter. The beamsplitter ratio is periodically calibrated using a pair of commercial power meters. For this comparison, the transfer standard and BB2 were exposed simultaneously to the reflected and transmitted laser beams, respectively, from the beamsplitter. The exposure period, controlled by opening and closing the shutter, was chosen such that the energy incident onto BB2 was within its operational limits. The responsivity of the transfer standard was then calculated by dividing the integrated voltage recorded from the transfer standard by the incident energy measured by BB2. This process was repeated multiple times and an average responsivity was found for the transfer standard.

\section{Results of Comparison}

Table 1 and 2 list the source of uncertainties for the NIST [4] and AFPSL measurements, and Table 3 lists the relevant measurement conditions associated with the comparison and the calculated results for both laboratories. The uncertainty estimates for the NIST and AFPSL laser energy measurements were assessed by use of NIST recommended guidelines [5]. The relative expanded uncertainties $(k=2)$ of the transfer standard responsivities measured at NIST and AFPSL were respectively $1.2 \%$ and $3.5 \%$. A small nonlinearity correction factor [6] was applied to the responsivity measured by the AFPSL to account for the slightly different power levels used.

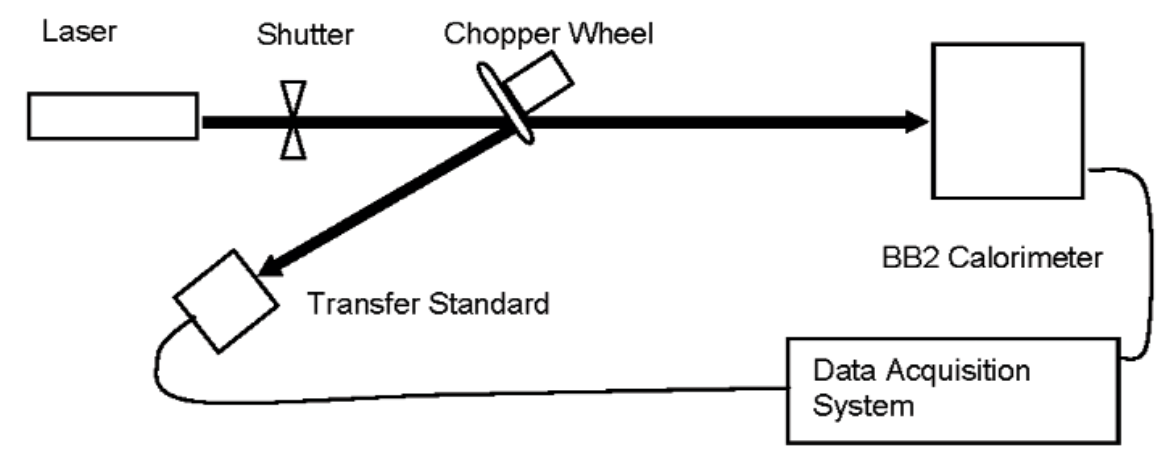

Fig. 2. AFPSL Measurement System. 
Table 1. Components of relative uncertainty for the NIST measurements, $k=1$

\begin{tabular}{lcc}
\hline \hline & $\begin{array}{c}\text { Type A } \\
\%\end{array}$ & $\begin{array}{c}\text { Type B } \\
\%\end{array}$ \\
\hline Test meter calibration (first time) & 0.033 & \\
Beamsplitter ratio (first time) & 0.039 & \\
Test meter calibration (second time) & 0.032 & \\
Beamsplitter ratio (second time) & 0.082 & \\
Optical shutter & 0.001 & \\
Linearity measurements & 0.028 & \\
Calorimeter inequivalence & & 0.144 \\
Calorimeter absorptivity & & 0.341 \\
Calorimeter heater leads & & 0.196 \\
Calorimeter electronics & 0.010 & 0.058 \\
Calorimeter electrical calibration & & 0.289 \\
Laser/system instability (absolute calibration) & & \\
Laser/system instability (linearity measurement) & 0.289 & \\
Polynomial truncation & & 0.058 \\
Attenuator ratio (absolute calibration) & & 0.090 \\
Attenuator ratio (linearity measurement) & & 0.090 \\
\hline
\end{tabular}

Table 2. Components of relative uncertainty for the AFPSL measurements, $k=1$

\begin{tabular}{lcc}
\hline \hline & $\begin{array}{c}\text { Type A } \\
\%\end{array}$ & $\begin{array}{c}\text { Type B } \\
\%\end{array}$ \\
\hline Digital voltmeter & & 0.058 \\
Ref. Meter: BB2 & & 1.732 \\
Beamsplitter ratio & & 0.404 \\
Counter/timer & & 0.058 \\
Non-linearity & & 0.104 \\
Test meter measurements & 0.062 & \\
\hline
\end{tabular}

Table 3. Comparison conditions and results

\begin{tabular}{|c|c|c|}
\hline & NIST & AFPSL \\
\hline Room temperature $\left({ }^{\circ} \mathrm{C}\right)$ & 23 & 21 \\
\hline $\begin{array}{l}\text { Transfer standard cooling water } \\
\text { temperature }\left({ }^{\circ} \mathrm{C}\right)\end{array}$ & 24.3 & 23.4 \\
\hline $\begin{array}{l}\text { Transfer standard cooling water } \\
\text { flow rate }(\mathrm{GPM})\end{array}$ & 1.0 & 1.2 \\
\hline Laser wavelength $(\mu \mathrm{m})$ & 10.6 & 10.6 \\
\hline Average laser power (W) & 809 & 780 \\
\hline $\begin{array}{l}\text { Laser beam size on the transfer } \\
\text { standard }(\mathrm{mm})\end{array}$ & 23 & 22.9 \\
\hline $\begin{array}{l}\text { Average responsivity of the transfer } \\
\text { standard }(\mathrm{mV} / \mathrm{W})\end{array}$ & 0.16035 & 0.16215 \\
\hline $\begin{array}{l}\text { Nonlinearity corrected responsivity, } \\
\text { referenced to } 809 \mathrm{~W}(\mathrm{mV} / \mathrm{W})\end{array}$ & 0.16035 & 0.16199 \\
\hline Relative expanded uncertainty $(k=2)(\%)$ & 1.2 & 3.5 \\
\hline $\begin{array}{l}\text { Relative measurement difference } \\
\text { [(AFPSL/NIST)-1] }(\%)\end{array}$ & \multicolumn{2}{|c|}{1.02} \\
\hline
\end{tabular}

\section{Conclusion}

The relative difference of $1.02 \%$ between calibration responsivities found by the two laboratories (NIST and AFPSL) in this comparison was well within the associated combined measurement uncertainties. Consequently, this result confirms that the two highenergy laser primary calorimeters and their corresponding measurement systems are essentially in agreement within experimented uncertainty. Thus, the modifications performed by NIST on BB2 presumably had no detrimental effect on their accuracy.

\section{References}

[1] R. L. Smith, T. W. Russell, W. E. Case, and A. L. Rasmussen, A Calorimeter for High-Power CW Lasers, IEEE Trans, Instrum. Meas., vol. IM-21 (1972).

[2] G. Chamberlain, P. A. Simpson, and R. L. Smith, Improvements in a Calorimeter for High-Power CW Lasers, IEEE Trans, Instrum. Meas., vol. IM-37 (1978).

[3] D. E. West and L. B. Schmidt, A System for Calibrating Laser Power Meter for the Range 5-1000 W, NBS Technical Note 685 (1977).

[4] X. Li, J. A. Hadler, C. L.Cromer, J. H. Lehman, and M. L. Dowell, High power laser calibrations at NIST, NIST Publication No. 32697 (2007).

[5] B. N. Taylor and C. E. Kuyatt, Guidelines for Evaluating and Expressing the Uncertainty of NIST Measurement Results, NIST Tech. Note 1297 (1994).

[6] X. Li, T. Scott, S. Yang, C. Cromer, and M. Dowell, Nonlinearity measurements of High-Power Laser Detectors at NIST, J. Res. Natl. Inst. Stand. Technol. 109, 429-434 (2004).

About the authors: Xiaoyu Li is an electronics engineer in the Optoelectronics Division of the NIST Electronics and Electrical Engineering Laboratory. Thomas Scott has since retired from NIST and was a physicist in the Optoelectronics Division of the NIST Electronics and Electrical Engineering Laboratory. Chris Cromer is a physicist in the Optoelectronics Division of the NIST Electronics and Electrical Engineering Laboratory. The National Institute of Standards and Technology is an agency of the U.S. Department of Commerce. David Cooper is a metrology engineer in the Photonics/Nucleonics Department of the Bionetics Corporation. Steven Comisford is a metrology technician in the Photonics/Nucleonics Department of the Bionetics Corporation. The Bionetics Corporation is currently under contract to the U.S. Air Force Primary Standards Laboratory. 